\title{
The effect of the surface structure of titanium alloy medical screws on their wear resistance
}

\author{
Svetlana Skvortsova ${ }^{1}$, Viktor Spektor ${ }^{1}$, Oksana Pozhoga ${ }^{1,{ }^{*}}$ and Olga Gvozdeva ${ }^{1}$ \\ ${ }^{1}$ Moscow Aviation Institute (National Research University), 125993 Volokolamskoe shosse 4, \\ Moscow, Russia
}

\begin{abstract}
In this work, the effect of vacuum ion-plasma treatment on the wear resistance of the medical screws surface made of VT6 titanium alloy is studied as well as on the mechanical characteristics of the screws in contact with the plate for osteosynthesis. It is shown that the TiN titanium nitride deposition on the screw head increases the surface microhardness by 3 times and also provides lowering the torque during removal of the screw out of the plate.
\end{abstract}

\section{Introduction}

In modern medicine, products for osteosynthesis are widely used for the surgical treatment of bone fractures. The type of structure for treatment is determined depending on the nature and complexity of the fracture - these may be plates, screws, pins, nails, etc. [1-3]. In particular, devices from titanium alloys which include plates and fixing screws are used in bone osteosynthesis for surgical reposition of bone fragments directly in the area of bone fracture [4]. Due to their design and biomechanical characteristics, such devices provide stable fixation of fragments in the correct position and maintain the functional axis of the segment and periosteal blood supply [5].

The successful use of structures made of titanium plates largely depends on the effectiveness and stability of their fixation to the bone, which in turn is determined by the material and properties of the screws. As surgical practice [3] shows, there is a need to increase the strength and wear resistance of titanium screw heads. In particular, when a screw is locked in a plate for osteosynthesis, the effect of the so-called "cold welding" occurs at the contact point of the threaded part of the screw head with the plate [4]. This, in turn, leads to complications in the removal of device after fracture treatment up to the thread is broken or the screw head is destroyed. Therefore, the development of a technology for modifying the surface of medical screws to create wear-resistant coatings is undoubtedly an urgent task.

Modern technological developments on modification of the surface structure in titanium alloys using wear-resistant coatings open up additional possibilities for new biocompatible stabilizing designs [6-8]. Thus, vacuum ion-plasma treatment (VIPT) which contributes to increasing the wear resistance of products has been widely used in the manufacturing, for

\footnotetext{
*Corresponding author: toksyk@gmail.com
} 
example, titanium alloy heads working in friction units paired with ultrahigh-molecularweight polyethylene $[9,10]$.

The aim of this work is to study the effect of vacuum ion-plasma treatment of medical screw heads made of VT6 titanium alloy on torque during insertion and removal of the screws into/out of the hole in a titanium plate for osteosynthesis.

\section{Materials and procedures}

Cortical screws made of VT6 (Ti-6Al-4V) titanium alloy according to the GOST R 50582 state standard (type HA 4) used in minimally invasive bone osteosynthesis for bone fractures are studied (Fig. 1). The cortical screw has a fine spherical thread ( $\varnothing 4 \mathrm{~mm}$ ) along the entire length of the body and a tapered thread on the spherical head $(\varnothing 6 \mathrm{~mm})$ with internal hexagon.

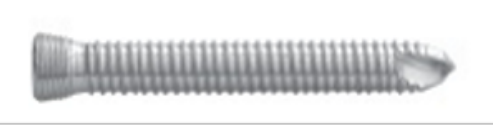

Fig. 1. HA 4 cortical screw for osteosynthesis with an initial surface state

The surface of the screw heads was subjected to vacuum ion-plasma treatment (nitriding and deposition of titanium nitride coating) in the upgraded «Bulat-6T» facility with nitrogen-argon atmosphere for $40 \mathrm{~min}$ at the temperature of $600{ }^{\circ} \mathrm{C}$. After nitriding, a layer of TiN titanium nitride was deposited on a part of the samples by the condensation method at the temperature of $600{ }^{\circ} \mathrm{C}$ for $30 \mathrm{~min}$.

Microstructure was studied using the Axio Observer A1m optic microscope (magnification is up to 1000 times) and the Image Expert Pro3 digital software intended for acquisition and analysis of the images.

Surface roughness $\left(R_{a}\right)$ was measured using the Hommel Tester T500 device. Microhardness was measured using the BUEHLER Micromet 5101 hardness-testing machine by a tetrahedral diamond pyramid (according to Vickers method) with a load of $0.5 \mathrm{~N}$ for $10-15$ seconds using the NEXSYS ImageExpert MicroHardness 2 software package.

The tightening and untightening torque during insertion and removal of the screws was determined according to the following method: the tested screws are inserted through the holes of a limited contact dynamic compression plate made of VT6 titanium alloy, and then they are screwed into pre-drilled holes of a wooden bar using a hexagonal screwdriver. Wood serves as an imitation of the cortical bone structure since it has similar mechanical characteristics $-\sigma_{B} \sim 110-140 \mathrm{MPa}, E \sim 12-16 \mathrm{GPa}$ [11]. To apply torque, the KD10-6.3 torque wrench with digital indication was used (measuring range of 2-10 N.m, resolution of $0.01 \mathrm{~N} \cdot \mathrm{m}$, relative error in measuring torque not more than $\pm 2 \%$ ).

Tightening of the tested screws was carried out with a torque of at least $6 \mathrm{~N} \cdot \mathrm{m}\left(M_{1}\right)$. During removal the torque was fixed when the screw was shifted $\left(M_{2}\right)$, then the relative change in the torques was determined. A part of the bars with plates and screws was immersed into $0.9 \% \mathrm{NaCl}$ aqueous solution simulating the human body environment at room temperature for 30 days. After holding in the solution, the removal torque was also measured. 


\section{Experimental Results and Discussion}

At the first stage of the work, the effect of vacuum ion-plasma treatment on the structure and surface properties of VT6 alloy products was studied.

Studies of the products internal structure were carried out using screws in the initial untreated state and after vacuum ion-plasma treatment (Fig. 2).

The structure of the screws in the initial state is represented by $\alpha$ and $\beta$ phases with a predominant fraction of the $\alpha$-phase with a polyhedral shape (Fig. 2 a).

Since during nitriding the products are heated to $600{ }^{\circ} \mathrm{C}$, which corresponds to incomplete annealing temperatures for $(\alpha+\beta)$-titanium alloys [12], the particles of the primary $\alpha$ phase become more globular after treatment (Fig. 2 b). The particle size is $5 \div 7$ $\mu \mathrm{m}$. The resulting structure complies with the requirements of the GOST R ISO 5832-3 state standard for the wrought Ti-6Al-4V alloy used in medicine.

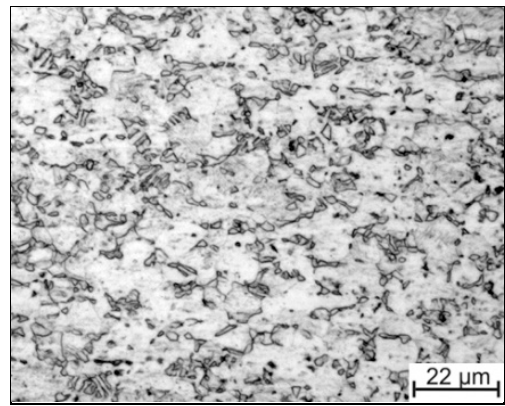

a)

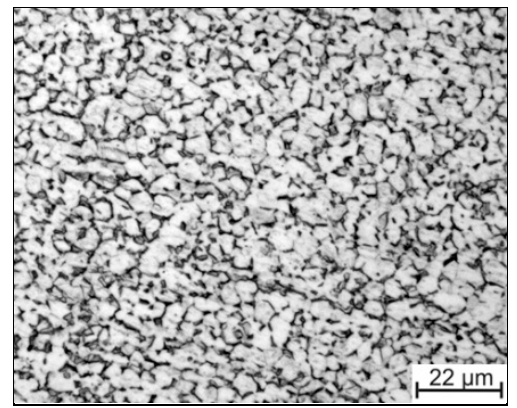

b)

Fig. 2. The structure of the VT6 alloy screw in the initial state (a) and after vacuum ion-plasma treatment (nitriding + TiN coating) (b).

The study of changes in microhardness, surface roughness and depth of the nitrided layer depending on the mode of vacuum ion-plasma treatment was carried out using "witness samples" cut from a rod of VT6 alloy with a diameter of $20 \mathrm{~mm}$. Preliminarily, the samples were polished until roughness parameter of $R_{a}=0.06 \mu \mathrm{m}$ was reached. The polished state allows the most efficient cleaning of the products surface before vacuum ionplasma treatment [13].

Studies showed that the microhardness of the VT6 alloy sample in the initial polished state was $3600 \mathrm{MPa}$ (Table 1). After vacuum ion-plasma nitriding, the surface microhardness increases approximately 2 times and amounts to $6300 \mathrm{MPa}$. Surface hardness increases due to the formation of nitrogen interstitial solid solution in the $\alpha$ and $\beta$ phases of the alloy $[10,14]$. Titanium nitride deposition on the surface of a pre-nitrided sample and immediately after polishing leads to an increase in the surface microhardness by 3 times compared with the initial state - to $11600 \mathrm{MPa}$ (Table 1).

Table 1. Microhardness and surface roughness of VT6 alloy samples depending on the modes of vacuum ion-plasma treatment

\begin{tabular}{|l|c|c|}
\hline Surface treatment & $\mathrm{HV}_{0.05}, \mathrm{MPa}$ & $\mathrm{R}_{\mathrm{a}}, \mu \mathrm{m}$ \\
\hline Initial state (polished) & 3600 & 0.06 \\
\hline Polishing + TiN coating deposition & 11600 & 0.19 \\
\hline Polishing + nitriding & 6300 & 0.07 \\
\hline Polishing + nitriding + TiN coating deposition & 11200 & 0.20 \\
\hline
\end{tabular}

Analysis of microstructures (Fig. 3) shows that vacuum ion-plasma nitriding results in the most solid and "clean" surface (Fig. 3 b), and the TiN deposition leads to the defects 
formation in the form of craters and a drop phase (Fig. 3 c, d) which is formed in the flow of titanium-nitrogen plasma [10].

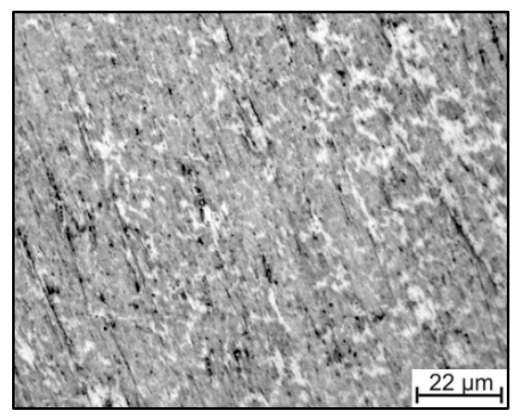

a)

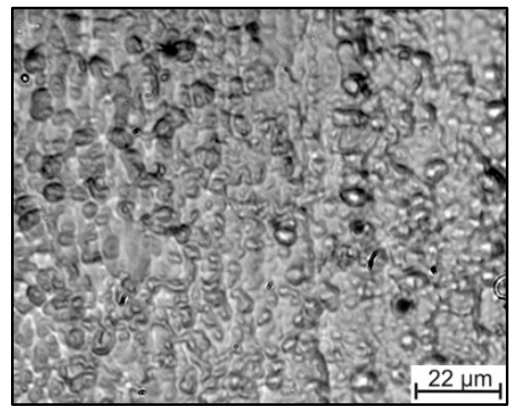

c)

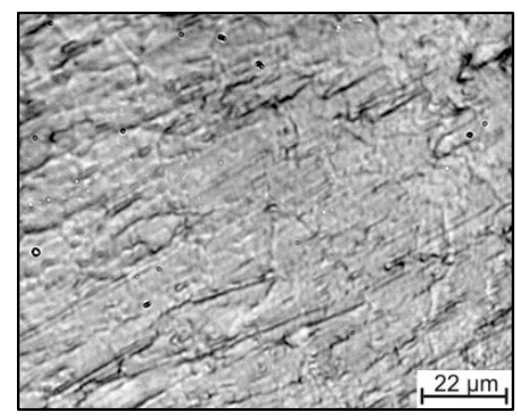

b)

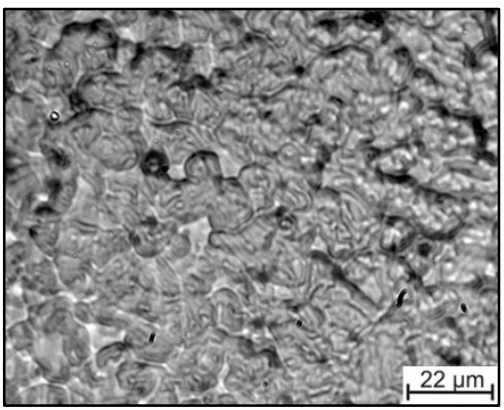

d)

Fig. 3. The surface microstructures of the VT6 alloy samples after vacuum ion-plasma treatment: a) the initial polished state; b) nitriding; c) nitriding + TiN coating; d) TiN coating

Also, depending on the mode of vacuum ion-plasma treatment, the surface microgeometry changes (see Table 1 ). Thus, nitriding has practically no effect on the surface roughness $\left(R_{a}=0.07 \mu \mathrm{m}\right)$, but after titanium nitride deposition the roughness parametr increases by more than 3 times up to $0.20 \mu \mathrm{m}$ (Table 1 ) due to the presence of irregularities and surface defects (see Fig. 3).

The depth of the nitrided layer was estimated by the beveled sample method using samples subjected to nitriding and complex vacuum ion-plasma treatment (nitriding + TiN deposition). Distribution of the microhardness depending on the depth of the modified surface layer was plotted based on the measurement results (Fig. 4).

The study showed that after treatment the depth of the nitrided layer in both cases is $29 \mu \mathrm{m}$ (Fig. 4 a, b). Moreover, the sample with deposited nitride is characterized by the presence of a nitride zone with a depth of $\sim 14 \mu \mathrm{m}$, when, with distance from the surface, the microhardness monotonically decreases to $6500 \mathrm{MPa}$ (Fig. $4 \mathrm{~b}$ ), and then the nitrogen diffusion zone follows. In this area, the decrease in hardness is due to a decrease in the nitrogen concentration in the solid solution.

At the second stage of the work, the influence of the surface state of HA 4 cortical screws made of VT6 titanium alloy treated by different modes of ion-plasma technology on the change in the torques during insertion and removal of the screws into/out of the hole in plate and a wooden bar was studied. 


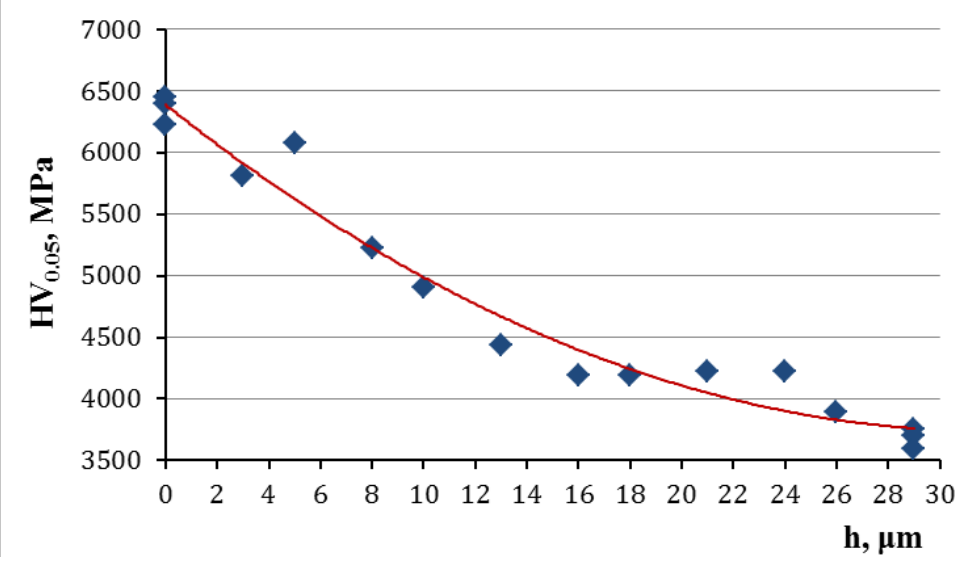

a)

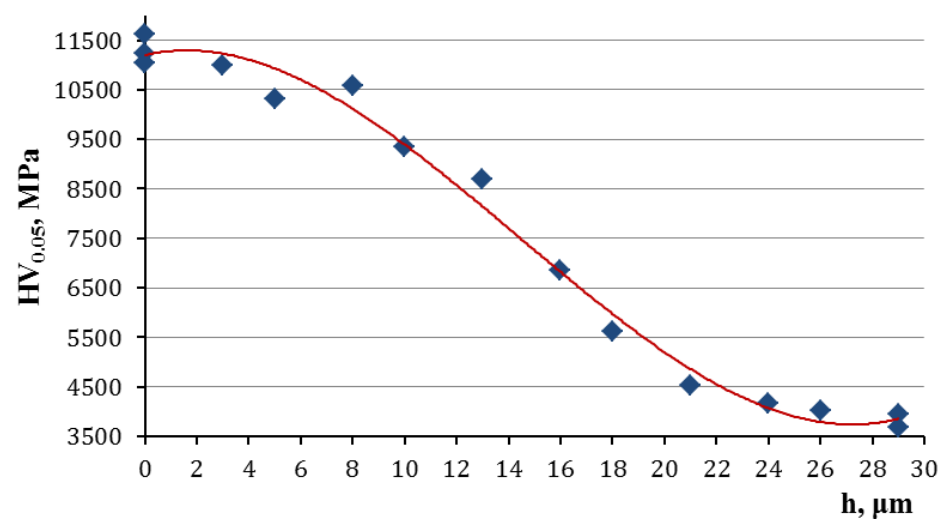

b)

Fig. 4. Microhardness values depending on the depth $(h)$ of the modified surface layer after vacuum ion-plasma treatment of the VT6 alloy samples: a) nitriding; b) nitriding + TiN coating

Since there is no regulatory documentation for this type of testing in Russia, the Russian standard GOST R 50581 and the standard of the American Society for Testing and Materials ASTM F543-17 are considered which establish the method of breaking test at torsion of the metal bone screws. However, there are no regulatory indicators for torques when the screw contacts the osteosynthesis plate. According to the standards, the minimum driving torque at breaking of cortical and cancellous screws varies from 0.2 to $6.2 \mathrm{~N} \cdot \mathrm{m}$ depending on the type of the screw. Therefore, in the work, a torque of at least $6 \mathrm{~N} \cdot \mathrm{m}$ was applied to tighten the tested screws in the plate hole.

At first, we studied the change in torque during insertion and removal of the screws into/out of a wooden bar without using a plate. The test results showed that the torque was $0.09 \mathrm{~N} \cdot \mathrm{m}$, which is less than the breaking torque specified in the standards. Therefore, when testing with a plate, the contribution of torque during screwing the screw body into a wooden bar can be neglected.

Next the change in the torques during insertion and removal of the VT6 alloy screws into/out of the plate hole and the wooden bar is studied after vacuum ion-plasma treatment of the screw heads (Fig. 5, 6). 


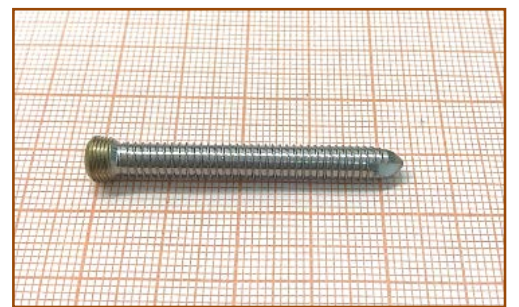

a)

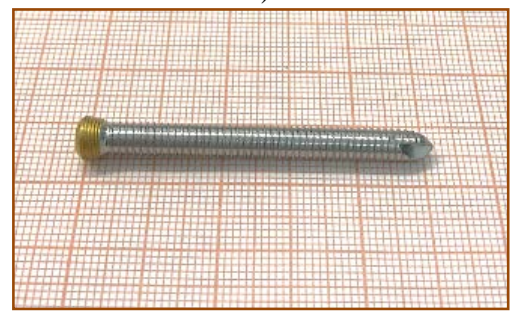

b)

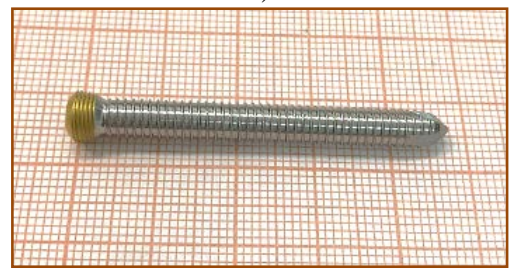

c)

Fig 5. Cortical screws from the VT6 alloy for bone osteosynthesis after vacuum ion-plasma treatment of the heads: a) nitriding; b) nitriding + TiN coating; c) TiN coating

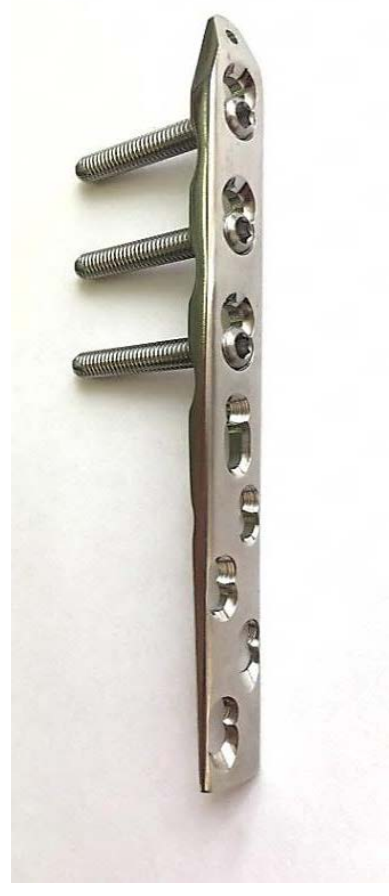

Fig 6. Tested screws in the titanium plate for bone osteosynthesis

The tests were carried out using three screws of each treatment mode and with the initial state of the surface. One part of the screws was tested under normal conditions (in air); the other part after insertion was immersed in $0.9 \% \mathrm{NaCl}$ aqueous solution for 30 days.

The tests results carried out in air showed that screws with an untreated surface of the heads were shifted during removal from the plate with greater force than during tightening — the torque increased on average by $\sim 4 \%$ (Table 2 ).

Table 2. Torques values obtained during insertion and removal of the screws into/out of the plate holes and wooden bar depending on the surface treatment of the screw heads (the table shows the average values of the measurement results)

\begin{tabular}{|l|c|c|c|c|c|c|}
\hline \multirow{2}{*}{$\begin{array}{l}\text { Surface treatment } \\
\text { of screw heads }\end{array}$} & \multicolumn{3}{|c|}{ In air } & \multicolumn{3}{|c|}{$\begin{array}{c}\text { After holding in } 0.9 \% \mathrm{NaCl} \text { aqueous } \\
\text { solution for 30 days }\end{array}$} \\
\cline { 2 - 7 } & $\mathrm{M}_{1}{ }^{*}, \mathrm{~N} \cdot \mathrm{m}$ & $\mathrm{M}_{2}{ }^{*}, \mathrm{~N} \cdot \mathrm{m}$ & $|\Delta|, \%$ & $\mathrm{M}_{1}, \mathrm{~N} \cdot \mathrm{m}$ & $\mathrm{M}_{2}, \mathrm{~N} \cdot \mathrm{m}$ & $|\Delta|, \%$ \\
\hline Untreated & 6.10 & 6.34 & $|3.9|$ & 6.07 & 5.45 & 10.2 \\
\hline TiN coating & 6.10 & 5.61 & 8.0 & 6.02 & 4.38 & 27.2 \\
\hline Nitriding & 6.08 & 5.33 & 12.3 & 6.06 & 4.94 & 18.5 \\
\hline $\begin{array}{l}\text { Nitriding + TiN } \\
\text { coating }\end{array}$ & 6.10 & 5.58 & 8.5 & 6.05 & 4.47 & 26.1 \\
\hline
\end{tabular}

${ }^{*} \mathrm{M}_{1}-$ tightening torque of the screw in plate hole; $\mathrm{M}_{2}-$ torque at shifting the screws during removal out of the plate 
VIP treatment of the head surface leads to a decrease in torque during removal by $12 \%$ and $8 \%$ for nitrided screws and those with titanium nitride coating, respectively (Table. 2). The difference between the obtained values can be explained by the difference in the roughness of the surface with titanium nitride and that of nitrided surface (see Table. 1).

After holding in $0.9 \% \mathrm{NaCl}$ aqueous solution for 30 days, the greatest difference in torques during insertion and removal was shown by screws with titanium nitride $-27 \%$ and 26\% for screws immediately coated with TiN and pre-nitrided, respectively (Table. 2). Vacuum ion-plasma nitriding of screw heads also leads to a decrease in torque by $18.5 \%$. Screws with an untreated surface of the heads showed the smallest change in torque 10.2\% (Table 2).

Inspection of the screws after all tests showed wear traces between the threads. Also, the threads on the screw heads underwent a partial deformation, and untreated and nitrided screws had more deformed turns at that.

The greater change in the torques after holding in solution compared to the test under normal conditions (see Table 2) is apparently explained by the difference in the friction forces in air and liquid environments. Probably, the solution acted as a lubricating fluid when it penetrated through the microscopic gaps during deformation of the screw and plate threads.

\section{Conclusions}

Thus, the studies have shown that vacuum ion-plasma treatment does not lead to significant changes in the internal structure of medical screws made of VT6 alloy. After ion-plasma nitriding, the surface hardness of VT6 alloy samples increases by 2 times compared with the initial state (from $3600 \mathrm{MPa}$ to $6900 \mathrm{MPa}$ ) due to the formation of nitrogen solid solutions of $\alpha$ and $\beta$ phases in the surface layer, and the presence of TiN titanium nitride increases the surface microhardness by 3 times up to $11600 \mathrm{MPa}$. The titanium nitride deposition changes the microgeometry of the samples surface; the roughness parameter increases from $0.06 \mu \mathrm{m}$ to $0.20 \mu \mathrm{m}$.

It was stated that vacuum ion-plasma treatment of the screw head surface contributes to decrease in the torque during removal of the screw preliminary tighthened into the hole of the titanium plate for osteosynthesis both in air and after holding the structure in $0.9 \% \mathrm{NaCl}$ aqueous solution. Moreover, the screws with titanium nitride coating show the most noticeable decrease - the torque decreases by almost $30 \%$.

Equipment support from the Centre of Collective Use “Aerospace Materials and Technologies” of MAI is gratefully acknowledged.

\section{References}

1. I.G. Belenkiy, G.D. Sergeev, Yu.V. Gudz, F.S Grigoryan, History, modern state and perspectives of development of plate internal fixation methods, Sovremennye Problemy Nauki i Obrazovaniya (Modern Problems of Science and Education), № 5, pp. 77-91 (2016).

2. M.E. Muller, M. Algower, R. Schneider, H. Willenger, Manual of Internal Fixation (Springer-Verlag Berlin Heidelberg, 1992).

3. AO Principles of Fracture Management, Edited by R. Buckley, Ch. Moran, Th. Apivatthakakul (Thieme (Stuttgart), 2018). 
4. K.K. Romanenko, A.I. Belostotsky, D.V. Prozorovsky, G.G. Golka, Functions and types of plates and screws in modern osteosynthesis, Ortopediya, Travmatologiya i Protezirovanie (Orthopedics, Traumatology and Prosthetics), №1, pp. 68-75 (2010).

5. E. Gautier, S. Perren, J. Cordey Effect of plate position relative to bending direction on the rigidity of a plate osteosynthesis. A theoretical analysis, Injury, v. 31, pp. 14-20, (2000).

6. A.M. Mamonov, V.S. Spektor, E.A. Lukina, S.M. Sarychev, The use of vacuum ionplasma nitriding to increase the wear resistance of medical implants, Titan, №2 (28), pp. 23-30 (2010).

7. S. Gokul Lakshmi, S. Tamilselvi, N. Rajendran, D. Arivuoli, Effect of $\mathrm{N}+$ ion implantation on the corrosion behaviour of Ti-6Al-7Nb and Ti-5Al-2Nb-1Ta orthopaedic alloys in Hanks solution, Journal of Applied Electrochemistry, v. 34, pp. 271-276 (2004).

8. J. Kim, W.J. Lee, H.W. Park, Mechanical properties and corrosion behavior of the nitriding surface layer of Ti-6Al-7Nb using large pulsed electron beam (LPEB), Journal of Alloys and Compounds, v. 679, pp. 138-148 (2016).

9. A.A. Il’in, A.M. Mamonov, V.N. Karpov, L.M. Petrov, A.V. Ovchinnikov, Complex technologies for the creation of wear-resistant high-loaded endoprostheses components for large joints from titanium alloys, Tekhnologiya Mashinostroeniya (Engineering Technology), №9, pp. 43-46 (2007).

10. A.A. Il'in, V.N. Fedirko, A.M. Mamonov, S.M. Sarychev, Yu.V. Chernyshova, The influence of complex processing technologies on the structural state of the surface and the operational properties of medical implants made of VT6 titanium alloy, Titan, №4 (46), pp. 4-11 (2014).

11. M.V. Gomonay, Proizvodstvo toplivnyh briketov. Drevesnoe syr'e, oborudovanie, tekhnologii, rezhimy raboty (Production of fuel briquettes. Wood raw materials, equipment, technologies, operating modes) (MGUL, Moscow, 2006).

12. B.A. Kolachev, B.I. Elagin, V.A. Livanov, Metallovedenie i termicheskaya obrabotka cvetnyh metallov i splavov (Metallurgy and heat treatment of non-ferrous metals and alloys) (MISiS, Moscow, 2005).

13. A.A. Il'in, V.V. Plihunov, L.M. Petrov, V.S. Spektor, Vakuumnaya ionno-plazmennaya obrabotka (Vacuum ion-plasma treatment) (Al'fa-M: INFRA-M, Moscow, 2014).

14. B.N. Arzamasov, A.G. Bratuhin, Yu.S. Eliseev, Ionnaya himiko-termicheskaya obrabotka splavov (Ion chemical-thermal treatment of alloys) (MSTU named after N.E. Bauman, Moscow, 1999). 